em 1890. Sobre a evolução da matéria, Carme Madrenas i Boadas, op. cit., pp. 28 a 42 . No direito brasileiro a concorrência desleal vem tratada no Decreto-Lei 7.903/45, tipificando-se os crimes nos incisos do art. 178, revigorado pelo vigente Codigo de Propriedade Industrial (art. 128). Considera-se crime, entre outros, o de publicar, pela imprensa ou qualquer outro meio falsa afirmaça em detrimento de concorrente com fim de obter vantagem indevida, bem como a divulga ção, sobre o concorrente, de falsa informação capaz de

${ }^{9}$ Carme Madrenas i Boadas, op. cit., pp. 25 e ss.

10 Segundo Carme Madrenas i Boadas "bacia los años 50 la evolución económica fuerza a buscar nuevas formulas en la composición de los intereses empresariales y trata ponerlos al día compatibilizzándolos con los intereses de ponerlos al dia compatibili zandolos con los intereses de los
consumidores. Ello supuso un desplazamiento de la líned fronteriza que separaba la protección del crédito y el principio de veracidad. El cambio repercutió también en la interpretación del principio de veracidad. La exigencia de transparencia en las prestaciones pasa a ser un objectivo urgente Pero, mientras la defesa de los intereses de los consumidores no adquiera sanción legal, se bará corresponder formal y tautologicamente con el interés en la 'transparencia' del mercado, el nuevo eufemismo que facilitará en adelante el consenso sobre los intereses que prevalecen effectivamente. La asimetria en la legitimación activa operará a modo de barrera que frena el manera que el principio de respeto de la verdad se entender manera que el principio de respeto de la verdad se entendera primordialmente en el sentido de remoción de los peligros de
desvio de la clientela" (Op. cit., pp. 33 e 44)

${ }^{11}$ Idem, p. 27.

$12 \mathrm{CDC}$, art. 4\%, III, in fine. A noção de "boa fé" que se deduz do Código não é aquela de matriz subjetiva, aplicável em matéria de direitos reais, onde considerada a intenção do agente, mas a boa fé objetiva, de incidência no campo obrigacional, a qual se identifica com um dever geral de correção na atuação no tráfico jurídico. Como afirma Vera Maria Jacob de Fradera ao comentar o dispositivo legal retro-referido, "a recepcāo, pelo Código de Defesa do Consumidor, da idéia de credo/confiança, é de grande relevância, porquanto, nos sistemas jurídicos latinos, de um modo geral, todo o ordenamento jurídico resulta da lei e a 'revolucão jurídica' faz-se por meio dela. Neste caso, modificaçōes haverão de produzir-se na relação de consumo, eis que um comportamento efetivamente regulado por uma regra de teor ético, é preconizado como presidindo no seu todo, a relaçăo". (A Interpretação da proibicão de publicidade enganosa e abusiva à luz do principio da boa fé: o dever de informar no Código de Defesa do Consumidor, comunicação exposta no III Congresso Internacional do Direito do Consumidor 1992, Canela, RGS e publicada na Revista Direito do Consumidor vol. 4, 1993. Escrevi brevemente sobre a distinção da boa fé objetiva e subjetiva em Crise Modificação da Idéia de Contrato no Direito Brasile ro, Revista Direito do Consumidor, vol, 3 , Säo Pauto Editora Revista dos Tribunais, 1992 p. 127, em especial p. 141
13 Carme Madrenas i Boadas, op. cit., p. 33, traduzi. ${ }^{14}$ Sobre a idéia de "concreção" ver Larenz, Metodologia da Ciência do Direito", tradução de J. de Sosa Brito, p. 15 Ver Karl Engish, Introdução à Ciência do Direito, Editora Fundação Calouste Gulbenkian, Lisboa, $1^{\mathfrak{a} e d i-}$ ção, pp.

Sobre a matéria, remeto à conferência apresentada por Eros Roberto Grau no III Congresso Brasileiro de Direito do Consumidor, Canela, RS, março de 1992, a qual comentei em estudos publicados na Revista Direito do Consumidor, vols. 4 e 5.

17 Para estas noções, ver os já citados estudos de Antonio H. V. e Benjamin, pp. 138 e ss, e Maria Elisabete Vilaça Lopes, p. 150

${ }^{18}$ Examinei a vedação a tais práticas em estudo publicado na Revista de Direito Público, vol. 97, p. 166 Evidentemente, ai se trata de "propaganda", e não de "publicidade", muito embora não tenha a Constituição seguido a distinção conceitual entre os dois termos.

${ }^{19}$ Maria Elisabete Vilaça Lopes, op. cit, p. 154, grifei 20 No mesmo sentido Antonio H. V. Benjamin, op cit., p. 186, como segue: "Publicidade que não quer assumir a sua qualidade é atividade que, de uma form ou de outra, tenta enganar o consumidor. $\mathrm{E} o$ engano, mesmo o inocente, é repudiado pelo Código de Defes do Consumidor".

21 Op. cit, p. 194, grifei.

22 Como já assinalei acima tal dever decorre da adstrição ao princípio da boa fé objetiva (art. $4^{\circ}$, III, in fine conjugado, para o que aqui concerne, com várias outras normas, tais como as do art. $6^{\circ}$, III e IV, o art. $8^{\circ}$ caput, art. $9^{\circ} \mathrm{e}$ art. 20 , caput, além daquelas referentes de modo específico à publicidade (arts. 30,36 a 38).

${ }^{23}$ In A Sociedade de Consumo, tradução de Arthur Morão, Ediçōes 70, Lisboa, 1981, p. 155

24 Op. cit. p. 174

25 Idem, ibidem, grifei.

${ }^{26}$ Para estas referências, Antonio H. V. Benjamin, op cit., pp. 174 e 175.

${ }^{27}$ Por esta expressão se designa, no direito da commo law, o caso de confusão deliberada entre os produto de um anunciante e os de seu competidor.

28. Op. cit., pp. 22 e 24, nota 1, traduzi. A fonte referida é Jeremy Philips, Passing off and trade libel: the "Big Mac case", J. Bus.L., 1986, pp. 240 a 242.

${ }^{29}$ Código Brasileiro de Auto-regulamentação publicitária, art. $9^{\circ}$.

${ }^{30}$ Assim Antonio H. V. Benjamin, op. cit. p. 195

1 Ver Mario Júlio de Almeida Costa, Direito das Obrigações, 5a edição, Almendina, Coimbra, 1991.

32 Antonio H.V. e Benjamin, idem, ibidem.

33 Idem, p. 197.

34 Idem, ibidem.

\title{
Ética notarial
}

Antônio Carlos Falcão Dornelles

Professor Assistente da Faculdade de Direito de Porto Alegre, onde prelecionou:

Filosofia de Direito, como assistente do Prof. Armando Câmara;

Direito Administrativo, como assistente do Prof. Paulo Pasqualini;

Prática Extra Forense, disciplina pela qual é atualmente responsável;

Vinculado ao Departamento de Direito Público e Filosofia do Direito;

Tabelião titular do Terceiro Tabelionato de Porto Alegre.

1. Como profissional do direito tem o notário sua ação norteada pela idéia do bem comum. Esta afirmativa resulta, é bem de ver, de uma investigação em torno dos conceitos do direito, da justiça, (sem a qual aquele não se formula) e do fim a que ambos se dirigem: o bem comum.

Não vamos, evidentemente, porque seria incabível nos limites deste trabalho, desenvolver todos os passos daquela investigação, mas podemos, sucintamente, apresentarlhes os resultados e, conseqüentemente, base da afirmativa que abre este trabalho.

Que é direito? Que é justiça? Que é bem comum?

Seguindo os passos do Prof. Armando Câmara, da Faculdade de Direito de Porto Alegre, cujos conceitos endossamos inteiramente, podemos formular os aludidos conceitos da seguinte forma: direito é um conjunto de princípios práticos, radicados na natureza racional e social do homem, descobertos pela razão, e destinados a regular as relações inter pessoais, em conformidade com a justiça. Justiça, por sua vez, é a conformidade de uma relação inter pessoal com o bem comum, vindo este a ser o conjunto das situações pessoais e sociais de vida que asseguram a realização dos fins totais do homem.

Justiça e direito, ambos, têm como fim o bem comum. O direito realiza-o diretamente; a justiça, indiretamente, através do direito.

Imbrica-se, a função notarial, a toda evidência, dentre aquelas situações sociais necessárias à realização do bem comum, do que é prova a universalidade da instituição notarial, encontrada dentro da organização urídica dos mais variados países, independentemente de sua ideologia política e de sua estrutura social e econômica.

Cabe, assim, indiscutivelmente, ao tabelião, uma parcela da responsabilidade social na realização do bem comum, homem do direito que é, como se disse linhas acima. Ora, "inverificável é o divórcio entre direito moral porque a moralidade não é uma virtude meramente subjetiva e, como tal, de projeção discutível na vida do homem como ser gregário, e nos destinos visíveis das sociedades. Ao invés, moralidade vale por aperfeiçoamento gradativo da espécie humana, por inclinação para a perfectibilidade da solidariedade social, e para a afirmação cada vez mais completa da justiça entre os homens. "(Queiróz Lima: "Princípios de Sociologia Jurídica, in "Introdução ao Estudo do Direito" de Roberto Piragibe da Fonseca)

2. Dentro da função notarial coexistem atividades diferenciadas, visto ser, a mesma, complexa, ao menos entre os povos que adotam a organização latina do notariado. Assim, o tabelião: a) - é consultor de seus clientes, a quem assessora e aconselha; ("Cumpre aos tabeliães indagar da identidade e capacidade das partes, e instruí-las sobre a natureza e conseqüências do ato que pretendem realizar" - Código de Organização Judiciária do Estado do Rio Grande do Sul, artigo 339). b) - preside seus atos jurídicos, realizando a política jurídica destes c) - reveste estes mesmos atos de forma instrumental adequada; d) - conserva os origi-

R. Fac. Direito UFRGS, Porto Alegre, 9(1): 89-93, nov. 1993 
nais dos mesmos a fim de fornecer certidões; e) - autentica-os através da fé pública de que é portador.

$\mathrm{Da}$ enumeração das várias atividades que coexistem dentro da função notarial, resulta, de modo inelutável, a afirmação de Zeballos, citado por Rufino Larraud - Professor da Faculdade de Direito de Montevidéu - em seu monumental "Curso de Derecho Notarial": "O dever ético da verdade alcança sua máxima energia na profissão notarial. Para o tabelião, a verdade é um fim: depositário da fé pública, seu dever primordial é assegurar a verdade; apresentar os fatos nos documentos por ele lavrados tal como se manifestam a seus sentidos e não de qual. quer outra maneira. Fé pública não é, naturalmente, sinônimo de verdade absoluta, mas é sinônimo de verdade."

3. Da mais alta e elevada importância social são, conseqüentemente, as funções desempenhadas' pelos tabeliães. Agindo, no desempenho de suas funções, como depositários da confiança das partes que perante eles comparecem, tornam-se, por via de conseqüência, depositários de grandes e valiosos interesses e, muitas vezes, os verdadeiros reguladores da vontade das mesmas partes. Não é novidade para alguém que esteja no exercício de função notarial o fato, muito comum, aliás, de mudarem as partes de intenção quanto aos atos que pretendiam levar a efeito, depois de uma consulta ao notário. E, note-se que, amiúde, trata-se de negócios jurídicos que comprometem todo o patrimônio de uma pessoa, ou atos que envolvem interesses de ordem moral de altíssima relevância, como o reconhecimento de um filho ilegítimo, ou de uma adoção. Por conseguinte, não exageram os autores ao exigirem do tabelião as qualidades morais enumeradas por Affonso Dionysio Gama em seu Manual Prático dos Tabeliães de Notas: "Verdadeiros; honestos; desinteressados; diligentes e ativos; generosos e compassivos; circunspectos; benevolentes e polidos; reservados; austéros e estóicos, - eis, no dizer dos escritores que do assunto se têm ocupado, as principais virtudes e qualidades que os tabeliães de notas devem possuir. 90
Verdadeiros, porque, incorrendo uma vez em falsidade, ficam suspeitosas as escrituras feitas depois, o que afugentará as partes;

Honestos, para imprimir em seus atos a confiança popular ao pé da fé oficial;

Desinteressados, porque devem contentálos os emolumentos taxados no Regimento de Custas; e para isso a lei lhes manda declarar, no fim das escrituras, as custas recebidas, o que hoje, por abuso, poucos fazem;

Diligentes $\mathrm{e}$ ativos para prontamente acudirem ao chamado das pessoas impedidas de comparecer em cartório, bem como para não demorarem a entrega dos tralados e mais papéis que lhes foram pedidos e, ainda, para não deixarem de fazer hoje que não pode ser adiado para amanhã;

Generosos e compassivos, a fim de prestarem seu ministério gratuito aos infelizes;

Circunspectos na conduta e no modo de trajar, para que consigam ganhar o respeito e as homenagens a que dá direito o cargo que ocupam;

Benevolentes e polidos, para testemunharem esmerada educação, companheira presuntiva do saber;

Reservados, para terem sob a mais estrita discrição os segredos confiados e as transações concluídas;

Austeros e estóicos, para repelirem, sem estrépito, as propostas indecorosas que, porventura, lhes sejam feitas.

4. Seguindo, em linhas gerais, o magistério de Rufino Larraud cuja competência não cansamos de proclamar, podemos dividir os deveres do tabelião em vários planos, quais sejam:

a) deveres do notário para consigo mesmo;

b) relações pessoais entre colegas;

c) relações entre colegas frente ao cliente;

d) relações do tabelião com seus clientes.

Vejamos cada item em particular.

a) deveres do notário para consigno mesmo

Deve o tabelião evitar tudo quanto possa comprometer seu decoro ou diminuir a consideração pública que deve sempre merecer. Desempenhando uma função em cujo exercício é condição de primordial importância a solvência moral do agente, é fácil prever que uma falha desta espécie diminui- rá sua capacidade de tal forma que comprometerá, não só seu interesse profissional, como também refletir-se-á sobre o prestígio social da classe.

Alérn do mais, outros deveres próprios da profissão incumbem ao notário, destacando-se, entre estes, a boa preparação jurídico profissional.

Acima de tudo, a função exige uma atuação honrada. Como afirma Larraud de forma lapidar: "Se este dever não viesse imposto pela própria natureza da função notarial e por outros fatores idealistas, seria imposta pelo próprio egoísmo: não é em vão que se afrma geralmente - embora muitos o esquecam - que é bom negócio ser honrado. profissional desonesto, mais cedo ou mais tarde é desmascarado e cai. O tabelião atua em um plano muito visível, e a observação permanente a que está submetido pela sociedade faz muito difícil uma simulação tão astuta que perdure todo o curso da vida. $O$ triunfo do profissional honesto - ao contrário - cedo ou tarde chega; só a morte ainda no início da carreira pode impedir que triunfe, e, às vezes, nem mesmo a morte o impede: sobrevive a memória enaltecida."

b) relações pessoais entre colegas

Um princípio fundamental deve regê-las: o da cordialidade e consideração recíprocas. Nem o fato da concorrência entre tabeliães de uma mesma localidade deve empanar este princípio que é, aliás, o fundamento do espírito de classe, tão importante para o fortalecimento da instituição.

c) relações entre colegas frente ao cliente

Evitar a todo custo a censura e a crítica a algum colega feita pelo tabelião frente a seu cliente. A censura feita a um companheiro afeta sutilmente todo o corpo profissional e volta-se sobre o próprio autor da crítica. O prestígio da classe deve ser resguardado principalmente neste momento de aglutinação de forças e soerguimento do notariado brasileiro. Pense-se, ademais, quanto custa construir uma reputação profissional - diz Baethgen - citado por Larraud - às vezes consome uma vida inteira de aplicação e inteireza moral; e pode ser atirada à sarjeta, de um dia para outro, por uma imputação habilmente construída, ou perversamente difundida.

Se é possível deixar de emitir opinião sobre um ato profissional alheio, é aconselhável fazê-lo de maneira discreta e ponderada, cuidando, entretanto, que a regra de discrição não se traduza em cumplicidade.

d) relações do tabelião com seus clientes

Vigora, aqui, um claro dever de lealdade frente ao cliente que confia ao notário seus segredos, seus bens, e sua tranqüilidade moral e material.

A obediência estrita ao regimento de custas se nos afigura dever ético inelutável do tabelião frente aos usuários de seu cartório e mesmo perante os colegas, sob pena de se assistir ao triste espetáculo da concorrência desleal, de fundo nitidamente comercial, entre os cartórios.

Além do mais, deve o tabelião, fiel à sua qualidade de portador da fé pública, absterse de praticar, ou sequer sugerir, a prática de atos simulados. "Não concebo a possibilidade de simular com fins líticos - diz Zeballos -, sempre me pareceu que falar de simulações lícitas é incorrer em contradição nos termos. O que ensina a vida é que, geralmente, o ato simulado oculta um propósito pouco nobre ou imoral. A simulação é, em si mesma, uma mentira, e não creio que, na conduta profissional - por mais que na vida seja possível mentir-se com fins muito puros -, deixe de ser uma transgressão ética" (Zeballos - "Deberes éticos del jurista"; in Curso de Derecho Notarial - Rufino Larraud)

Outrossim, "el notario debe hacer algo más que asesorar a las partes y recoger fielmente su voluntad o sus manifestaciones; debe además buscar para los problemas que ante él se planteen las soluciones que estime más justas y convenientes, y tratar, por todos los medios lícitos a su alcance, de conseguir que prevalezcan. Es cierto que no puede obligar a los interesados a realizar sus actos en forma distinta a la que ellos en definitiva decidan, porque carece de autoridad coactiva; pero en caso de que los otorgantes insista en actos que, aunque jurídicamente lícitos, el juzgue lesivos para alguno 
de ellos o que pueden conducir a situaciones que no encajen en su concepto de lo justo, debe denegar su intervención. Por ello, el notario se convierte en cierto modo en juez de las relaciones jurídicas de los particulares en el momento de su nacimiento; ahora bien, se trataría de un juez que aplicaría no sólo las normas jurídicas en su letra y en su espíritu, sino sus própias concepciones sobre lo justo y lo injusto en el campo de la normación de relaciones derivadas de la autonomía privada." (González Enriquez).

5. Segundo o ensinamento unânime dos autores que se têm ocupado do assunto, a organização corporativa do notariado, sob a forma de Colégios Notariais, representa relevante papel também no plano da disciplinação ética da classe.

Com efeito, a colegiação "é a forma de organização que melhor e mais tipicamente responde às questões colocadas pela vigilância do profissional com respeito à sua conduta como integrante da classe e à exata observância dos deveres do cargo, assim como, em geral, acerca do decoro devido à condição de que está investido". (Curso de Derecho Notarial - Rufino Larraud).

Frise-se, contudo, que a forma de associação civil de que se reveste o notariado brasileiro no presente momento, com seu Colégio Notarial - pessoa jurídica de direito privado - não atende integralmente os fins a que se propõe, particularmente no plano da fiscalização ético-profissional: a filiação é inteiramente voluntária, não abarca a totalidade dos tabeliães $e$, por conseguinte, não se pode afirmar, a rigor, que represente a classe, nem tem possibilidade de impor sanções disciplinares. Como frisa Larraud "a associação civil cumpre, precipuamente, fins genéricos de melhoramento cultural de corporação, promovendo a cooperação e a solidariedade de seus integrantes com vistas ao atendimento de seus próprios interesses materiais e seus bens espirituais e morais".

Somente sob a forma de pessoa jurídica de direito público, à semelhança, por exemplo, da Ordem dos Advogados do Brasil, poderá o Colégio Notarial do Brasil atender com eficiência à função de órgão dísciplinador da classe.

É este mais um motivo a justificar a batalha pela criação de um colégio notarial com a hierarquia de pessoa de direito público, além de outras vantagens de sobejo conhecidas.

6. Se ao juiz cabe julgar e ao advogado defender, ao tabelião compete precaver acautelar. Caracterizada está, aí, a função precípua do notário dentre os profissionais do direito. Irrelevante é o fato de se não exigir, entre nós, o título de bacharel para o exercício da função. $O$ tabelião vive do direito e para o direito. Dá forma jurídica a interesses econômicos e morais que the são levados. É, pois, jurista no sentido amplo da expressão. Sendo-o, a ele aplicam-se as magníficas palavras de Roberto Piragide da Fonseca com que encerramos este trabalho:

"Que o jurista seja honesto, não porque - acompanhando o pensamento de Celso a missão do jurista seja lidimamente sacerdotal, dado que propagar, defender e distribuir a virtude da justiça constitui tarefa inquestionávelmente revestida de sacralidade.

Que o jurista saiba exercitar eticamente o direito, porque, em caso contrário, não se farão esperar os resultados da opcão infeliz

Que o jurista seja idealista, não porque, - seguindo o texto dos Santos Livros -, o ideal é que diviniza o homem e atesta que ele é realmente feito à semelhança e imagem do Criador.

- Não por isso, porque os homens, em sua maioria são hostis, e mesmo invulneráveis, aos argumentos que acusam uma procedência sobrenatural. - Mas porque, - esse o argumento que de fato convence -, jurista despido de ideal é autômato desprezível, possivelmente uma eficiente máquina de amealhar moedas, mas, de qualquer forma, um "robot" de carne e osso, condenado à rotina que desencanta, ao mimetismo que desespera, e, mais que tudo, à mediocridade que humilha."

\section{Bibliografia}

Larraud, Rufino. Curso de Derecho Notarial.

Gama, Affonso Dionysio. Manual Prático dos Tabeliâes de Notas.
Fonseca, Roberto Piragibe da. Introduçáo ao Estudo do Direito.

Telles, .Corrêa. Manual do Tabelião.

Mora, José Ferrater. Dicionário de Filosofia.

Álvarez, Manuel de La Câmara y Martinez, José Roán. La Formación y Selección del Notario.

---. Código de Organizacão Judiciária do Estado do Rio Grande do Sul. 